\title{
Characterization of the Response of Ornamental Graminoids to Attempted Infection by Sclerotinia sclerotiorum
}

\author{
Michelle A. Grabowski ${ }^{\dagger}$ and Dean K. Malvick, University of Minnesota, Department of Plant Pathology, Saint Paul, MN 55108
}

\begin{abstract}
Sclerotinia sclerotiorum causes Sclerotinia stem rot (SSR) (also called white mold), resulting in stem rot and death of many common herbaceous ornamental plant species. Resistant plants would be useful to manage SSR; however, the host range of S. sclerotiorum is unclear. The goal of this study was to determine how the ornamental graminoids Pennisetum glaucum, Setaria italica, Juncus inflexus, Carex flagellifera, Isolepis cernua, and Acorus gramineus respond to inoculation with S. sclerotiorum. Plants were inoculated in the field and in controlled environments at $13,16,19$, or $22^{\circ} \mathrm{C}$ with or without wounding, and evaluated for SSR. Inoculated detached leaves were stained to examine infection and oxalate oxidase production. A. gramineus developed SSR in field and controlled

environments. Sclerotinia stem rot was not observed on $P$. glaucum in field environments. The disease developed on P. glaucum and $S$. italica in controlled environments, and severity increased with decreasing temperature and wounding. J. inflexus, C. flagellifera, and I. cernua developed no or minor symptoms of SSR in field and controlled environments. Mycelia penetrated A. gramineus leaves $24 \mathrm{~h}$ after inoculation (HAI) and $P$. glaucum at $48 \mathrm{HAI}$, but did not penetrate $J$. inflexus at 24 , 48 , or 96 HAI. Oxalate oxidase was not detected in inoculated leaves of these ornamental graminoids. The results illuminate S. sclerotiorum's interactions with monocots and broaden the understanding of SSR resistance in ornamental grasses.
\end{abstract}

Sclerotinia sclerotiorum (Lib.) de Bary is a necrotrophic fungal plant pathogen that causes significant economic damage to a wide range of plant species including vegetables, legumes, oil seed crops, and ornamental flowering plants (Gleason et al. 2009; Hartman et al. 2015; Harveson et al. 2016; Koike 2007). The disease is commonly known as Sclerotinia stem rot (SSR) or white mold. Although symptoms vary among hosts, infection typically progresses into the plant stem, resulting in wilt and death of all parts distal to the infection. Sclerotia produced by S. sclerotiorum can survive many years in soil and may either germinate as mycelia or produce apothecia capable of releasing large numbers of airborne ascospores (Bolton et al. 2006; Schwartz and Steadman 1978). The wide host range of S. sclerotiorum combined with its ability to produce long-term survival structures and disseminate airborne ascospores make SSR a challenging disease to manage.

In ornamental landscape plantings, S. sclerotiorum causes stem rot, wilt, and death of many common herbaceous ornamental plants including Zinnia spp., Petunia spp., Antirrhinum spp., Tagetes spp., and Salvia spp. (Boland and Hall 1994; Farr and Rossman 2017). In the Midwestern United States, plant death often occurs in mid-to-late summer when replacement plants are no longer available. This results in large areas of dead plants or bare soil, which is an unacceptable condition for high value, high visibility landscape beds.

A potential disease management option for landscape managers is to choose plant species that resist infection by S. sclerotiorum. Unfortunately, ornamental plants are not commonly tested or bred for resistance to SSR, and the complete host range of S. sclerotiorum is not well defined. Over 400 species of plants from 75 families are reported to be susceptible to S. sclerotiorum (Boland and Hall 1994;

${ }^{\dagger}$ Corresponding author: M. A. Grabowski; E-mail: magrabow@umn.edu

Funding: This project was funded by the Minnesota Turf and Grounds Foundation.

This paper is a portion of a thesis by Michelle A. Grabowski in fulfilling degree requirements for the University of Minnesota.

*The $\boldsymbol{e}$-Xtra logo stands for "electronic extra" and indicates that five supplementary figures are published online.

Accepted for publication 26 August 2018.

(c) 2019 The American Phytopathological Society
Farr and Rossman 2017). The majority of landscape ornamentals susceptible to $S$. sclerotiorum are herbaceous dicotyledons from numerous plant families (Daughtrey et al. 1995; Gleason et al. 2009). Grabowski and Malvick (2015) demonstrated that five commonly grown dicotyledonous herbaceous ornamentals that do not appear on the host lists of $S$. sclerotiorum were susceptible to infection in field and controlled environments. In contrast, monocotyledonous ornamental plants in the Araceae and Cannaceae varied in susceptibility to $S$. sclerotiorum, with several highly resistant species identified (Grabowski and Malvick 2017). Ornamental grasses comprise another group of potentially resistant plants that have not been tested for resistance or susceptibility and do not appear on host lists for S. sclerotiorum.

Of the five families of monocotyledonous plants listed as hosts to $S$. sclerotiorum, the only graminoid family included is the Poaceae (Boland and Hall 1994). The two most recently published host lists do not agree on which members of the Poaceae are hosts. Boland and Hall (1994) reported that plants from nine genera of Poaceae are hosts of S. sclerotiorum, whereas Farr and Rossman (2017) listed plants in eight genera as hosts. The genera Zea, Sorghum, Setaria, and Triticum occur on both host lists. Although corn, sorghum, and wheat are listed as hosts, S. sclerotiorum is not considered a pathogen of importance in these crops, despite their use in locations where environmental conditions frequently favor development of SSR (Bockus et al. 2010; Warren and Frederiksen 1986; White and Munkvold 2016).

Species in several genera of Poaceae are listed as hosts of S. sclerotiorum due to infection of grain in storage, but it is unclear if other plant parts can also be infected (Hysek et al. 1986; Miclauş et al. 1988; Richardson 1990). Plants within many genera of Poaceae appear on published disease indices that do not include a description of symptoms or severity of the infection (Anonymous 1960; Conners 1967; Galloway 1935; Poole 1922). Only the reference for Setaria viridis contains a description of disease signs and symptoms (Burke et al. 1957). Thus, the extent of S. sclerotiorum's infection capabilities within graminoids remains unknown.

Ornamental grasses in the Poaceae, Cyperaceae, Juncaceae, and Acoraceae are available to landscape managers and valuable in ornamental landscape beds. None has been tested for resistance or susceptibility to $S$. sclerotiorum. The objectives of this study were to (i) compare the susceptibility of select ornamental grasses from these four families to $S$. sclerotiorum under different environment conditions, (ii) determine if temperature or wounding affect disease development, and (iii) characterize how ornamental graminoids respond to 
inoculation by examination of fungal growth and oxalate oxidase production in leaves. These studies expand knowledge of this pathogen's interactions with monocots and provide information on relative resistance of ornamental grasses for use in landscape beds infested with S. sclerotiorum.

\section{Materials and Methods}

Isolate preparation. Three isolates of $S$. sclerotiorum from diverse hosts were arbitrarily chosen for this study. Isolate ORN010 was isolated from a petunia plant in Chaska, MN; FC002 was isolated from a soybean plant in Renville County, MN; and VEG001 was isolated from green beans sold as produce in St. Paul, MN. All isolates were used in field studies, but only ORN010 was used in the growth chamber because previous studies demonstrated no difference in virulence or host $\times$ isolate interactions among the isolates (Grabowski and Malvick 2015, 2017). Isolates were grown and stored as described previously (Grabowski and Malvick 2015).

Plant materials. Ornamental grasses widely available to landscape managers in the Midwestern United States and representing diverse families and genera were selected for these studies. These included cultivars of species in six genera of graminoids from four families (Table 1). Seed of Pennisetum glaucum and Setaria italica (Johnny's Selected Seeds, Fairfield, Maine) were planted in 10.2$\mathrm{cm}$-square pots containing a composted bark potting mix (Sungro Horticulture, Agawam, MA) and maintained in a greenhouse with $12 \mathrm{~h}$ light at $25^{\circ} \mathrm{C}$ and $12 \mathrm{~h}$ darkness daily at $20^{\circ} \mathrm{C}$. Seedlings were fertilized by watering pots to saturation 7 days after emergence with 20-20-20 soluble fertilizer (Everris NA, Inc., Dublin, OH), and Osmocote 14-14-14 (Everris NA, Inc.) was added to pots 2 weeks after emergence at $0.005 \mathrm{~g} / \mathrm{cm}^{3}$. Plants were grown for approximately 10 weeks until 8-10 fully expanded leaves were present. Juncus inflexus, Isolepis cernua, Acorus gramineus, and Carex flagellifera were purchased as transplants in 10.2-cm-square pots (Linder's Greenhouses Inc., Roseville, MN). Zinnia elegans $\times$ angustifolia 'Profusion White' transplants (Linder's Greenhouses Inc.) were included in trials as a susceptible control. All plants were maintained in a greenhouse with $12 \mathrm{~h}$ light at $25^{\circ} \mathrm{C}$ and $12 \mathrm{~h}$ darkness daily at $20^{\circ} \mathrm{C}$ prior to planting in field trials.

Field studies of disease susceptibility. Studies were arranged in a randomized complete block design with six blocks and conducted at two field locations containing Waukegan silt loam in Falcon Heights, $\mathrm{MN}$ in 2011. Plants were transplanted into the field plots at one location on 8 June and at the other location on 14 June. Experimental units were $107 \times 107 \mathrm{~cm}$ plots containing nine plants arranged in three rows of three plants each, with $35 \mathrm{~cm}$ spacing between plants. One row of Profusion Cherry zinnias was planted as a border around each block to help maintain even moisture within the plots and reduce edge effects. Plants were watered daily for $20 \mathrm{~min}$ with an oscillating sprinkler to promote establishment prior to inoculation. Osmocote 14-14-14 (340 kg/ha) was applied to the plots 2 weeks after planting.

Table 1. Ornamental grasses evaluated for susceptibility to Sclerotinia sclerotiorum

\begin{tabular}{|c|c|c|c|}
\hline Scientific name & Cultivar & $\begin{array}{c}\text { Common } \\
\text { name }\end{array}$ & Family \\
\hline $\begin{array}{l}\text { Acorus gramineus } \\
\text { Sol. ex Aiton }\end{array}$ & Ogon & Sweet Flag & Acoraceae \\
\hline Carex flagellifera Colenso & Toffee Twist & Sedge & Cyperaceae \\
\hline $\begin{array}{l}\text { Isolepis cernua } \\
\text { (Vahl) Roem. \& Schult. } \\
\text { (Syn. Scirpus cernuиs) }\end{array}$ & Fiber Optic Grass & Low Bulrush & Cyperaceae \\
\hline Juncus inflexus L. & Blue Mohawk & Reed & Juncaceae \\
\hline $\begin{array}{l}\text { Pennisetum glaucum } \\
\text { (L.) R. Br. } \\
\text { (Syn. Cenchrus } \\
\text { americanus) }\end{array}$ & Purple Majesty & Millet & Poaceae \\
\hline $\begin{array}{l}\text { Setaria italica (L.) } \\
\text { P. Beauv. }\end{array}$ & Lime Light Spray & Foxtail millet & Poaceae \\
\hline
\end{tabular}

Plots were inoculated with a mixture of equal quantities of sorghum seed colonized individually by the three isolates of $S$. sclerotiorum (Grabowski and Malvick 2015). The inoculum mixture was spread evenly over the plant canopy at 86.5 liters/ha on 4 August 2011 when the susceptible Profusion White zinnia had grown to achieve canopy closure, and again on 11 August. Irrigation was applied for $5 \mathrm{~min}$ immediately after inoculation and subsequently applied three times daily for $10 \mathrm{~min}$ for the duration of the study. Daily maximum and minimum temperatures were 22.7 to $29^{\circ} \mathrm{C}$ and 15.5 to $23^{\circ} \mathrm{C}$, respectively.

Disease severity and incidence were recorded every 14 days after inoculation (DAI) until plants were killed by frost. Disease incidence was recorded as the number of plants per plot that were infected with S. sclerotiorum based on signs and symptoms. Symptomatic tissue from any plant with unidentifiable symptoms was surface sterilized and plated on $1 / 2 \times$ potato dextrose agar (PDA, Becton, Dickinson and Company, Franklin Lakes, NJ) to confirm infection by $S$. sclerotiorum. Disease severity was recorded as percent plant canopy missing within plots due to plant death from SSR. The area under disease progress curve (AUDPC) was calculated (Madden et al. 2007) for a 28 -day period for field 2 and a 42-day period for field 1 . The difference in period of observation for the two fields was the result of planting date differences and an early killing frost.

Disease susceptibility at different temperatures in controlled environments. The plant entries (Table 1) were grown as described above and evaluated for resistance in a growth chamber at $13,16,19$, and $22^{\circ} \mathrm{C}$. Experiments were arranged in a randomized complete block design with three blocks, and one plant per block. Sclerotia of $S$. sclerotiorum isolate ORN010 were placed on $1 / 2 \times$ PDA 5 days prior to the experiment and incubated at $22^{\circ} \mathrm{C}$ to promote mycelial growth. An $8 \mathrm{~mm}$ square of $1 / 2 \times$ PDA containing the leading edge of the fungal colony was secured to a lower stem of each plant with a sterile toothpick inserted $0.6 \mathrm{~cm}$ into the stem. Mock inoculated plants were treated in a similar fashion using sterile $1 / 2 \times$ PDA. Three 4- to 6-week-old Phaseolus vulgaris 'Provider' plants grown from seed in 10.2-cm-square pots were included as susceptible checks at each temperature. Plants were inoculated by placing the fungus on cut stems as described previously (Grabowski and Malvick 2015). Soil was thoroughly watered, then each plant was misted with water until run-off, covered with a clear plastic bag, and placed in a growth chamber (Environmental Growth Chambers, Chagrin Falls, $\mathrm{OH}$ ) set to one of the four temperatures with a 12-h photoperiod and $90 \%$ relative humidity. Bags were removed 3 DAI. At 28 DAI, plants were cut at soil level, bisected vertically, and internal and external lesion length was measured. The experiment was performed twice at each temperature.

Disease susceptibility in response to wound inoculation. A. gramineus, $P$. glaucum, and $J$. inflexus were selected to represent susceptible, intermediate, and resistant responses to SSR, respectively. Plants were evaluated to determine the effect of wounding on infection by $S$. sclerotiorum. The experiment was arranged in a randomized complete block design with three blocks, one plant per block, and was conducted twice. Treatments included basal stem inoculation with or without wounding, leaf inoculation with or without wounding, and mock inoculated control. Basal stem inoculations were conducted as described above, with or without wounding the stem with a sterile toothpick. The agar plug was secured to the stem with Parafilm (Bemis Company, Inc., Oshkosh, WI) in wounded and nonwounded plants. Leaves were wounded by removing the distal half of a fully expanded leaf with a sterile razor blade; and then an agar plug containing S. sclerotiorum, prepared as described above, was placed on the cut edge. In nonwounded leaves, the agar plug was placed on the adaxial surface at the midpoint of the leaf. In both wounded and nonwounded leaves, the agar plug was attached with Parafilm. Mock inoculated controls were wounded at the leaf and stem as described above, and sterile 1/2× PDA was applied. Because $J$. inflexus lacks true leaves, the plants were wounded at the base of the stem as described above or the stem was inoculated $7.5 \mathrm{~cm}$ below the apical point with or without wounding. Plants were incubated for $72 \mathrm{~h}$ in a plastic bag following inoculation as described above and 
maintained at $13^{\circ} \mathrm{C}$ in a growth chamber with a 12 -h photoperiod and $90 \%$ RH. Lesion length and number of leaves killed due to infection was determined 28 DAI. The leading edge of the infection from plants with uncharacteristic symptoms was plated on 1/2× PDA and incubated 14 days at $22^{\circ} \mathrm{C}$ to determine if the pathogen was present.

Microscopic examination of leaf response to inoculation. $A$. gramineus, $P$. glaucum, and J. inflexus were selected to represent susceptible, intermediate, and resistant responses to SSR, respectively. Plants were grown in the greenhouse as described above. Fully expanded leaves were harvested, and 6-cm sections were cut from the middle of leaves with a sterile razor blade and placed on wet, sterile filter paper (Whatman International, Maidenstone, England) in a sterile $100 \times 15 \mathrm{~mm}$ petri dish. An agar plug containing S. sclerotiorum isolate ORN010, prepared as described above, was placed at the center of each leaf segment on the adaxial surface. Mock inoculated controls received sterile $1 / 2 \times$ PDA. Petri dishes were sealed with Parafilm and incubated at $22^{\circ} \mathrm{C}$ with $10 \mathrm{~h}$ light and 14 h darkness. To determine if $S$. sclerotiorum produced infection cushions on nonplant surfaces, an agar plug of isolate ORN010 was also placed on a glass microscope slide, a glass slide wrapped in colored tape (Fisherbrand, Houston, TX), and a glass slide covered with colored construction paper (Wexford, Deerfield, IL) saturated with Millipure filtered water. The slides with inoculated nonplant surfaces were sealed in petri dishes and incubated as described above.

Leaves and inoculated nonplant surfaces were examined at 24 and 48 HAI. J. inflexus leaves were also examined at 96 HAI because no evidence of penetration was observed earlier. Agar plugs were removed from leaves and the inoculation site was examined with a Nikon SMZ 18 stereomicroscope (Nikon Corp., Tokyo, Japan) to determine the presence or absence of infection cushions. The section of leaf below the inoculation site was sectioned with a microtome. The cross sections were submerged in lactophenol blue stain (Sigma Aldrich, Inc., St. Louis, MO) for $1 \mathrm{~min}$ and then in water for $1 \mathrm{~min}$ prior to examination with a Nikon Eclipse NiU light microscope to observe the extent of fungal growth and infection.

Examination of oxalate oxidase activity in inoculated leaf tissue. A. gramineus, $P$. glaucum, J. inflexus, C. flagellifera, and I. cernua were grown as described above. S. italica was not included in the study due to insufficient quantities of seed. Wheat (Triticum aestivum 'Morocco') and barley (Hordeum vulgare 'Bowman') were used as positive controls. Seed of wheat and barley were planted in 10.2-cm-square pots, grown as described above for $P$. glaucum and $S$. italica. Fully expanded leaves were harvested from all plant entries. Eight 6-cm-long sections were cut from the middle of the leaves with a sterile razor blade and placed on wet filter paper in a petri dish as described above. An agar plug containing isolate ORN010, prepared as described above, was placed at the center, adaxial surface of each leaf segment. Mock inoculated controls received only sterile $1 / 2 \times$ PDA. Petri dishes were sealed with Parafilm (Bemis Company, Inc.) and incubated at $22^{\circ} \mathrm{C}$ for $1,4,6$, or $24 \mathrm{~h}$, with $10 \mathrm{~h}$ light and $14 \mathrm{~h}$ darkness. One inoculated and one mock inoculated leaf segment were inspected per time interval. Agar plugs were removed and leaf tissue was placed into 1.2-ml glass vials containing $1 \mathrm{ml}$ of oxalate oxidase detection buffer (Dumas et al. 1995; Orshinsky et al. 2012) for $1 \mathrm{~h}$ at $22^{\circ} \mathrm{C}$. Then leaves were removed and examined for dark blue staining indicative of oxalate oxidase activity with a Nikon Eclipse NiU light microscope. This experiment was conducted twice.

To determine if the cuticle interfered with detection of oxalate oxidase, leaf segments of J. inflexus, I. cernua, C. flagellifera, A. gramineus, $P$. glaucum, and wheat were harvested, inoculated, and incubated as described above. After $48 \mathrm{~h}$, one leaf per plant entry was placed into the oxalate oxidase detection buffer for $1 \mathrm{~h}$ and examined as described above. Another leaf segment per plant entry was placed in a glass vial containing undiluted xylene and incubated for $24 \mathrm{~h}$ to remove the cuticle (Hilu 1984). Leaves were removed from the xylene, dried with a clean paper towel, placed into the oxalate oxidase detection buffer for $1 \mathrm{~h}$, and examined as described above. This experiment was conducted three times.
Statistical analysis. Data from field experiments and wound inoculation trials were right skewed, not normal, and treatment variance was not equal (JMP Pro 13 software, SAS Institute Inc., Cary, NC). This could not be corrected with standard data transformations, and therefore nonparametric methods were used for data analysis. Friedman's test was used to calculate a $\chi^{2}$ value for the model and a $P$ value for treatments. Treatments with a $P$ value less than or equal to 0.01 were compared using Wilcoxon's rank testing to determine significance of differences between treatments. Data from the variable temperature study were normally distributed, and variances were determined to be homogeneous between repeated experiments using Hartley's Fmax test. Data from replicate experiments were combined and analyzed with ANOVA. Tukey's honestly significant difference was used to separate means (JMP Pro 13 software, SAS Institute Inc.).

\section{Results}

Susceptibility of ornamental grasses to Sclerotinia stem rot in field environments. Disease incidence and severity 14 DAI for the susceptible control Profusion White zinnia averaged across both fields were 94 and 39\%, respectively, indicating favorable conditions for SSR development (data not shown). J. inflexus, I. cernua, C. flagellifera, and $P$. glaucum were symptom free throughout the field study. A. gramineus was the only grass to develop symptoms of infection under the field conditions. Elongate tan lesions developed on the rhizomes, infection spread into leaf clusters, and leaves turned tan and died. The AUDPC for disease incidence and severity for all grasses was significantly lower than the susceptible zinnia control (Table 2). S. italica plants did not tolerate transplanting and died shortly after planting in the field.

Influence of temperature on disease susceptibility in a controlled environment. Plants of the susceptible check, $P$. vulgaris, developed stem rot and died by $10 \mathrm{DAI}$ at all temperatures, indicating favorable conditions for SSR in the growth chamber (data not shown). Death of $P$. vulgaris and stem lesion length in J. inflexus, C. flagellifera, and I. cernua were unaffected by temperature (Figs. 1 and 2). In contrast, lesion length in A. gramineus, P. glaucum, and $S$. italica varied with temperature, and the effect of temperature on disease severity varied by plant entry (Figs. 1 and 2). Lesion length for $P$. glaucum and $S$. italica increased greatly as temperature decreased, and was significantly greater at $13^{\circ} \mathrm{C}$ than at all other temperatures (Figs. 1 and 2). Lesion length for A. gramineus did not differ between 13,16 , and $19^{\circ} \mathrm{C}$, but was significantly lower at $22^{\circ} \mathrm{C}$ (Figs. 1 and 2).

$J$. inflexus, C. flagellifera, and I. cernua were resistant to S. sclerotiorum at all temperatures (Figs. 1 and 2). Internal and external lesion length for J. inflexus, C. flagellifera, and I. cernua did not differ significantly between inoculated and mock inoculated plants at any temperature (Table 3). Small, brown lesions $(<1.0 \mathrm{~cm})$ were observed on 8 and $21 \%$ of inoculated C. flagellifera and J. inflexus plants, respectively. Presence of $S$. sclerotiorum in symptomatic tissue was confirmed by isolation, and a small sclerotium was present in $8 \%$ of the stems from these species (Supplementary Fig. S1). No signs

Table 2. Area under disease progress curve (AUDPC) for incidence and severity of Sclerotinia stem rot in field-inoculated ornamental grasses

\begin{tabular}{lrrrrr}
\hline & \multicolumn{2}{c}{ Incidence AUDPC } & & \multicolumn{2}{c}{ Severity AUDPC } \\
\cline { 2 - 3 } & Field 1 & Field 2 & & Field 1 & Field 2 \\
\hline Carex flagellifera & $0 \mathrm{c}^{\mathrm{z}}$ & $0 \mathrm{c}$ & & $\mathrm{b}$ & $0 \mathrm{~b}$ \\
Juncus inflexus & $0 \mathrm{c}$ & $0 \mathrm{c}$ & $0 \mathrm{~b}$ & $0 \mathrm{~b}$ \\
Pennisetum glaucum & $0 \mathrm{c}$ & $0 \mathrm{c}$ & $0 \mathrm{~b}$ & $0 \mathrm{~b}$ \\
Isolepis cernua & $0 \mathrm{c}$ & $0 \mathrm{c}$ & $0 \mathrm{~b}$ & $0 \mathrm{~b}$ \\
Acorus gramineus & $211 \mathrm{~b}$ & $146 \mathrm{~b}$ & $22 \mathrm{~b}$ & $7 \mathrm{~b}$ \\
Zinnia elegans $\times$ angustifolia & $3344 \mathrm{a}$ & $2048 \mathrm{a}$ & & $2132 \mathrm{a}$ & $942 \mathrm{a}$ \\
\hline
\end{tabular}

${ }^{\mathrm{z}}$ AUDPC was calculated for a 28-day period for field 2 and a 42-day period for field 1. All statistical comparisons are among entries within each field. Values with the same letter within a column are not significantly different at $\alpha=0.001$ by Wilcoxon's rank testing. 
or symptoms were observed in inoculated I. cernua plants, and the pathogen was not isolated.

Symptoms of SSR developed on A. gramineus, P. glaucum, and $S$. italica at all temperatures. Although SSR resulted in plant death of the susceptible check $P$. vulgaris by 10 DAI, SSR in these ornamental graminoids did not progress to plant death 28 DAI. Stem lesion length of $P$. glaucum and $S$. italica was greater than mock inoculated controls at all temperatures (Table 3 ). Symptoms of infection in $P$. glaucum and $S$. italica plants included dark brown to black elongate stem lesions that extended into the pith. Pith cells were degraded, creating a hollow elongate cavity lined with white mycelia and containing sclerotia (Supplementary Fig. S2). Internal discoloration of the pith extended beyond visible lesion length on the epidermis of the stem of $P$. glaucum and $S$. italica in both directions at 13 and $16^{\circ} \mathrm{C}$ (data not shown). Stem lesion length on A. gramineus was greater than mock inoculated controls at 13,16 , and $19^{\circ} \mathrm{C}$ (Table 3). Although symptoms of infection were visible at $22^{\circ} \mathrm{C}$, lesion length did not significantly differ from mock inoculated controls at this temperature (Table 3). An elongate tan lesion developed on A. gramineus rhizomes, infection spread into leaf clusters, and leaves turned tan and died (Supplementary Fig. S3). Mycelia and sclerotia were observed in infected leaf clusters of $A$. gramineus.

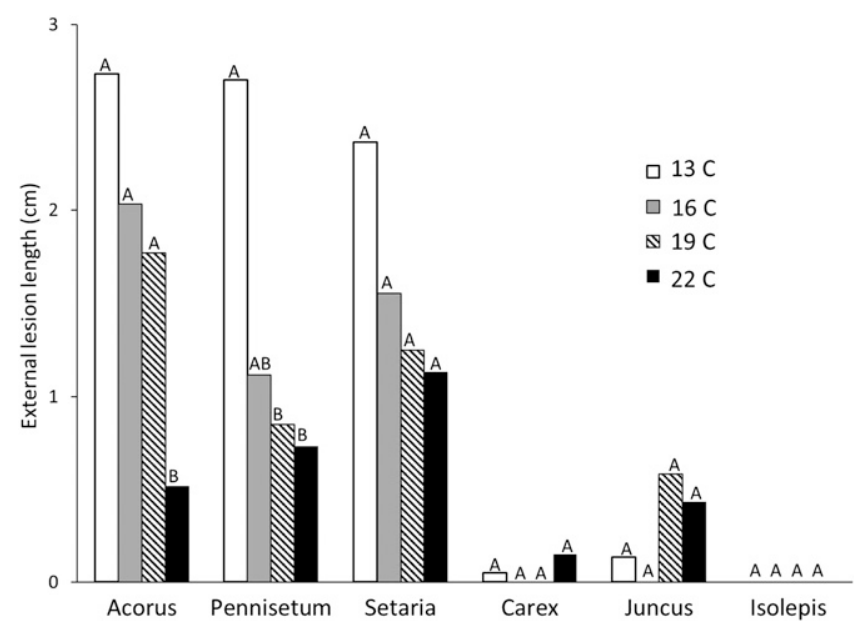

Fig. 1. External lesion length on stems of ornamental grasses inoculated with Sclerotinia sclerotiorum and incubated at four temperatures. Values with the same letter within a plant entry are not significantly different at $\alpha=0.01$ by Tukey's honestly significant difference.

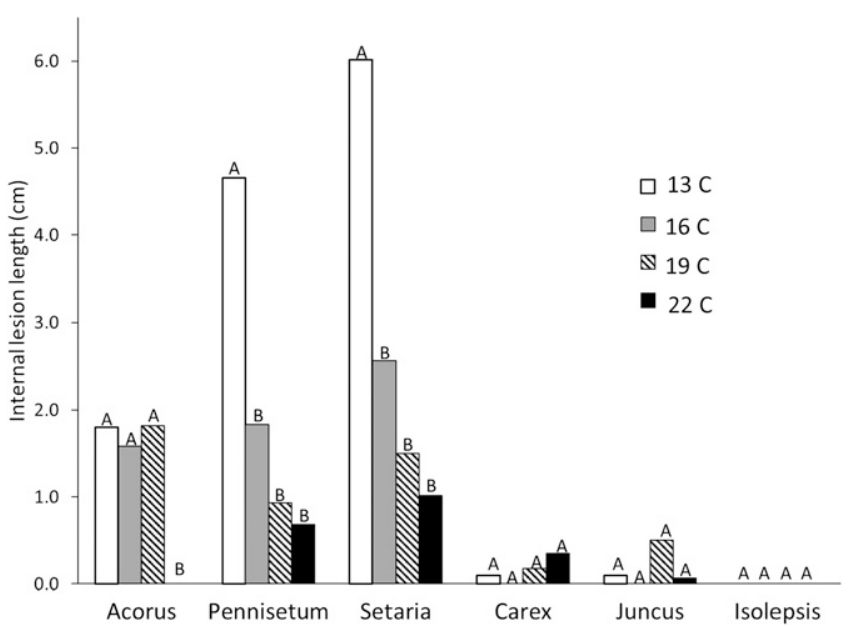

Fig. 2. Internal lesion length in stems of ornamental grasses inoculated with Sclerotinia sclerotiorum and incubated at four temperatures. Values with the same letter within a plant entry are not significantly different at $\alpha=0.01$ by Tukey's honestly significant difference.
Influence of wounding on disease development and resistance. Wounding was required for infection of the most resistant plant entry, $J$. inflexus, and it increased disease severity in the moderately resistant plant entry $P$. glaucum, but did not affect severity in the susceptible plant entry A. gramineus. Necrosis developed in inoculated leaves and stems of A. gramineus, regardless of wound treatment, and lesion length did not differ between wounded and nonwounded plants (Table 4). External stem lesion length and leaf lesion length of inoculated $P$. glaucum did not differ between wounded and nonwounded plants (Table 4). Infection progressed into stem pith tissue only in wounded stems (Table 4), resulting in significantly greater internal lesion length in wounded $P$. glaucum stems. $J$. inflexus developed a measurable necrotic lesion only when wounded. Lesion length on apical wounded stems was significantly greater than nonwounded and mock inoculated stems. Lesion length on basal wounded stems did not differ significantly from nonwounded or mock inoculated plants. In J. inflexus, S. sclerotiorum was isolated from $100 \%$ of apical wounded stems and $33 \%$ of basal wounded stems (Table 4).

Microscopic examination of the infection site. S. sclerotiorum initiated the infection process on the resistant, intermediate, and susceptible plant entries, J. inflexus, $P$. glaucum, and A. gramineus, respectively, as indicated by development of multiple infection cushions on leaves of all inoculated plants at 24 and 48 HAI (Supplementary Fig. S4). Infection cushions did not develop on nonplant surfaces, i.e., glass slides, slides with lab tape, or slides with paper.

Table 3. External stem lesion length on six ornamental grasses 28 days after inoculation with Sclerotinia sclerotiorum and incubation at 13,16, 19, and $22^{\circ} \mathrm{C}$

\begin{tabular}{lllll}
\hline & \multicolumn{4}{c}{ Stem lesion length $(\mathbf{c m})$} \\
\cline { 2 - 5 } & $\mathbf{1 3}^{\circ} \mathbf{C}$ & $\mathbf{1 6}^{\circ} \mathbf{C}$ & $\mathbf{1 9}^{\circ} \mathbf{C}$ & $\mathbf{2 2}^{\circ} \mathbf{C}$ \\
\hline Acorus gramineus & $2.7 \mathrm{a}^{\mathrm{y}}$ & $2.0 \mathrm{a}$ & $1.8 \mathrm{a}$ & $0.5 \mathrm{bc}$ \\
Setaria italica & $2.4 \mathrm{a}$ & $1.6 \mathrm{ab}$ & $1.3 \mathrm{ab}$ & $1.1 \mathrm{a}$ \\
Pennisetum glaucum & $2.7 \mathrm{a}$ & $1.1 \mathrm{~b}$ & $0.9 \mathrm{~b}$ & $0.7 \mathrm{ab}$ \\
Juncus inflexus & $0.1 \mathrm{~b}$ & $0.0 \mathrm{c}$ & $0.6 \mathrm{bc}$ & $0.4 \mathrm{bc}$ \\
Carex flagellifera & $0.1 \mathrm{~b}$ & $0.0 \mathrm{c}$ & $0.0 \mathrm{c}$ & $0.2 \mathrm{c}$ \\
Isolepis cernua & $0.0 \mathrm{~b}$ & $0.0 \mathrm{c}$ & $0.0 \mathrm{c}$ & $0.0 \mathrm{c}$ \\
Mock inoc. control $^{\mathrm{z}}$ & $0.00 \mathrm{~b}$ & $0.00 \mathrm{c}$ & $0.00 \mathrm{c}$ & $0.00 \mathrm{c}$
\end{tabular}

y Values in a column followed by the same letter are not significantly different at $\alpha=0.05$ by Tukey's honestly significant difference.

${ }^{\mathrm{z}}$ All mock inoculated controls had the same value. Although statistical analysis was conducted on individual mock inoculated entries, mock inoculated data are displayed as one representative entry.

Table 4. Lesion length on wounded or nonwounded leaves and stems of Juncus inflexus, Acorus gramineus, and Pennisetum glaucum 28 days after inoculation with Sclerotinia sclerotiorum and incubation at $13^{\circ} \mathrm{C}$

\begin{tabular}{lcccc}
\hline & \multicolumn{4}{c}{ Lesion length (cm) } \\
\cline { 2 - 5 } Treatment & $\begin{array}{c}\text { Juncus } \\
\text { inflexus }\end{array}$ & $\begin{array}{c}\text { Acorus } \\
\text { gramineus }\end{array}$ & $\begin{array}{c}\text { Pennisetum } \\
\text { glaucum }\end{array}$ \\
\cline { 2 - 5 } External & Internal \\
\hline Leaf nonwounded & $0.0 \mathrm{~b}^{\mathrm{x}}$ & $12.8 \mathrm{~b}^{\mathrm{y}}$ & $0.0 \mathrm{a}^{\mathrm{x}}$ & $0.0 \mathrm{a}^{\mathrm{x}}$ \\
Leaf wounded & $5.3 \mathrm{a}$ & $11.6 \mathrm{~b}$ & $0.0 \mathrm{a}$ & $0.0 \mathrm{a}$ \\
Stem nonwounded & $0.0 \mathrm{~b}$ & $32.1 \mathrm{c}$ & $0.9 \mathrm{~b}$ & $0.0 \mathrm{a}$ \\
Stem wounded & $0.1 \mathrm{~b}$ & $25.0 \mathrm{bc}$ & $1.9 \mathrm{~b}$ & $3.0 \mathrm{~b}$ \\
Noninoculated & $0.0 \mathrm{~b}$ & $0.0 \mathrm{a}$ & $0.0 \mathrm{a}$ & $0.0 \mathrm{a}$ \\
control & & & & \\
\hline
\end{tabular}

x Values in a column followed by the same letter are not significantly different at $\alpha=0.001$ by Wilcoxon's rank testing.

y Values in a column followed by the same letter are not significantly different at $\alpha=0.01$ by Wilcoxon's rank testing.

${ }^{\mathrm{z}}$ Leaf inoculation occurred at the midpoint of a true leaf of A. gramineus and $P$. glaucum, and $7.5 \mathrm{~cm}$ below the apical tip of $J$. inflexus stems. 
The ability of $S$. sclerotiorum to infect leaves and the rate of infection varied among plant entries. Infection and colonization of epidermal cells, mesophyll cells, and elaioplasts of A. gramineus were observed at 24 HAI (Supplementary Fig. S5), but leaf sections were too degraded to be sectioned at $48 \mathrm{HAI}$. Infection cushions developed on the surface of $P$. glaucum leaves $24 \mathrm{HAI}$, and penetration and colonization of epidermal and mesophyll cells was observed 48 HAI. No penetration of $J$. inflexus tissue was observed at 24, 48, or $96 \mathrm{HAI}$, although multiple infection cushions were present at all three time points. By $96 \mathrm{HAI}$, the infection cushions on inoculated J. inflexus were degraded, flattened, and lacked structure; and the cuticle, mesophyll cells, and sclerenchyma below the infection cushions were discolored brown but remained intact and turgid.

Examination of oxalate oxidase activity in inoculated leaf tissue. Dark staining indicative of oxalate oxidase production was observed at the edge of lesions in the positive controls, barley and wheat, at 24 and 48 HAI. With the aid of magnification, staining was observed in cell walls and stomata around the lesion edge in these plants. No staining was observed macroscopically or microscopically at the inoculation point of A. gramineus, J. inflexus, I. cernua, P. glaucum, or $C$. flagellifera at any time point. Cuticle removal with xylene did not affect lesion development or oxalate oxidase staining.

\section{Discussion}

This study demonstrates a range of susceptibility and resistance responses to $S$. sclerotiorum in inoculated ornamental graminoids. Although none of the ornamental graminoids in this study appear on the host list, $S$. sclerotiorum was able to infect and create a lesion in five of the six plant entries under some experimental conditions. As a result, A. gramineus, $P$. glaucum, $S$. italica, $C$. flagellifera, and $J$. inflexus should be added to the U.S. National Fungus Collections Fungal Database (USDA, ARS) as hosts for S. sclerotiorum, as this list represents all reported fungus-host associations. I. cernua is the only ornamental graminoid included in these studies that did not become infected with S. sclerotiorum under any conditions included in this study.

Useful levels of resistance were identified in several ornamental graminoids. All ornamental graminoids tested exhibited much lower SSR severity compared with susceptible controls zinnia and common bean. I. cernua was immune to infection under all conditions examined in the study. C. flagellifera and J. inflexus were considered resistant due to their ability to limit the infection to a few centimeters around the infection site, resulting in minimal overall damage to the plants. $P$. glaucum and $S$. italica demonstrated moderate resistance to SSR, with wounding and temperature playing a significant role in disease development. A. gramineus was susceptible to SSR under all conditions tested, but infection never progressed to plant death as was observed in susceptible controls.

This is the first histological study describing attempted infection of graminoids by $S$. sclerotiorum. Studies have previously shown that S. sclerotiorum forms domed infection cushions with multiple penetration hyphae positioned perpendicular to the host surface to initiate an infection (Lumsden and Dow 1973; Lumsden and Wergin 1980). In this study, $S$. sclerotiorum formed infection cushions on detached leaves of the three ornamental graminoids examined, but not on the mock leaf surfaces. This indicates that $S$. sclerotiorum recognized the graminoids as potential hosts. The recognition, however, did not lead to successful infection and disease development in all of the species examined.

Three different plant responses to the initial recognition and attempted infection by $S$. sclerotiorum were observed in this study. First, penetration and infection was complete and rapid. A. gramineus became infected $24 \mathrm{~h}$ after inoculation (HAI), indicating a lack of defense mechanisms to prevent initial infection. This is similar to what was described for infection of susceptible bean by S. sclerotiorum (Abawi et al. 1975; Lumsden and Dow 1973). In the second type of response, infection by $S$. sclerotiorum was delayed but not prevented, as was observed for $P$. glaucum. Third, infection was prevented, as observed with $J$. inflexus, which prevented penetration through the 96-h viable lifespan of the infection cushion. This result and the fact that infection occurred after wounding suggests that
$J$. inflexus possesses structural defense mechanisms that inhibit the ability of S. sclerotiorum to penetrate plant tissue and initiate infection. In addition, discoloration of the cuticle, epidermal, and mesophyll cells occurred at the infection site in J. inflexus at $96 \mathrm{HAI}$, indicating potential production of plant defense compounds that inhibit further infection and/or disease development. For example, these could include production phenols, phytoalexins, pathogenesis related proteins, cell wall degrading enzymes, and proteins associated with the oxidative burst as has been reported in resistance responses to S. sclerotiorum in other hosts (Bazzalo et al. 1985; Hegedus et al. 2008; Prats et al. 2003; Urdangarín et al. 1999; Wang et al. 2012; Zhao et al. 2007).

Production of oxalate oxidase is a known defense response against fungal pathogens, including $S$. sclerotiorum (Hurkman and Tanaka 1996; Zhou et al. 1998). Oxalic acid has been identified as an important pathogenicity factor for $S$. sclerotiorum, and transgenic introduction of the oxalate oxidase gene into susceptible crops has increased resistance to $S$. sclerotiorum (Cessna et al. 2000; Cober et al. 2003; Donaldson et al. 2001; Godoy et al. 1990; Guimaraes and Stotz 2004; Hu et al. 2003; Marciano et al. 1983; Noyes and Hancock 1981). In this study, oxalate oxidase production was not detected in response to inoculation with $S$. sclerotiorum in any of the ornamental graminoids, although it was produced in the wheat and barley used as positive controls. These results indicate that resistant ornamental grasses utilize defense mechanisms other than oxalate oxidase against $S$. sclerotiorum.

All ornamental graminoids that became infected with S. sclerotiorum in this study reduced colonization of host tissue and limited disease development compared with susceptible controls, i.e., zinnia and common bean. As noted above, multiple defense mechanisms were likely utilized by the different plant species to accomplish this. In addition, the fact that disease development was not equally influenced by temperature in the different plant species also suggest that different temperature-dependent defense mechanisms likely affect tissue colonization and disease progression in the graminoid species examined. Disease severity for the two species from the Poaceae, $S$. italica and $P$. glaucum, had an inverse relationship with temperature. Disease severity in A. gramineus was lower at $22^{\circ} \mathrm{C}$ compared with the consistent severity measured at 13,16 , and $19^{\circ} \mathrm{C}$. However, temperature did not affect disease severity in C. flagellifera or J. inflexus. These results indicate that different temperature-dependent defense mechanisms may affect tissue colonization and disease progression in the Poaceae plant entries and A. gramineus, and that one or more temperature-independent defense mechanisms may restrict colonization of host tissue in C. flagellifera and J. inflexus.

The ornamental graminoids with the highest levels of resistance identified in this study may be useful in ornamental landscape plantings where SSR is a persistent problem. Furthermore, some of the likely different resistance mechanisms detected in the ornamental graminoids challenged by $S$. sclerotiorum are potentially novel and may be useful in breeding for resistance to this pathogen. Further research is needed to characterize and identify these resistance mechanisms. Novel resistance mechanisms could potentially be utilized to increase resistance to SSR in susceptible hosts, perhaps through use of transgenic methods as was done with oxalate oxidase (Cober et al. 2003; Donaldson et al. 2001; Hu et al. 2003). This work advances our understanding of the host-pathogen interactions between S. sclerotiorum and graminoids.

\section{Acknowledgments}

Thanks to Dr. Bruna Bucciarelli and Dr. Angela Orshinsky for assistance in the staining and microscopy studies.

\section{Literature Cited}

Abawi, G. S., Polach, F. J., and Molin, W. T. 1975. Infection of bean by ascospores of Whetzelinia sclerotiorum. Phytopathology 65:673-678.

Anonymous. 1960. Index of Plant Diseases in the United States. U.S. Dep. Agric. Handb. 165.

Bazzalo, M. E., Heber, E. M., Del Pero Martinez, M. A., and Caso, O. H. 1985. Phenolic compounds in stems of sunflower plants inoculated with Sclerotinia 
sclerotiorum and their inhibitory effects on the fungus. J. Phytopathol. 112: 322-332.

Bockus, W. W., Bowden, R. L., Hunger, R. M., Murray, T. D., and Smiley, R. W. 2010. Compendium of Wheat Diseases and Pests. American Phytopathological Society, St. Paul, MN.

Boland, G. J., and Hall, R. 1994. Index of plant hosts of Sclerotinia sclerotiorum. Can. J. Plant Pathol. 16:93-108.

Bolton, M. D., Thomma, B. P. H. J., and Nelson, B. D. 2006. Sclerotinia sclerotiorum (Lib.) de Bary: biology and molecular traits of a cosmopolitan pathogen. Mol. Plant Pathol. 7:1-16.

Burke, D. W., Gomes, J. C., and Foeppel, W. G. 1957. Observations on Sclerotinia wilt of beans in northeastern Colorado. Plant Rep. 41:72-73.

Cessna, S. G., Sears, V. E., Dickman, M. B., and Low, P. S. 2000. Oxalic acid, a pathogenicity factor for Sclerotinia sclerotiorum, suppresses the oxidative burst of the host plant. Plant Cell 12:2191.

Cober, E. R., Rioux, S., Rajcan, I., Donaldson, P. A., and Simmonds, D. H. 2003. Partial resistance to white mold in a transgenic soybean line. Crop Sci. 43:92-95.

Conners, I. L. 1967. An annotated index of plant diseases in Canada and fungi recorded on plants in Alaska, Canada and Greenland. Publ. Res. Br. Can. Dep. Agric. 1251.

Daughtrey, M. L., Wick, R. L., and Peterson, J. L. 1995. Compendium of Flowering Potted Plant Diseases. American Phytopathological Society, St. Paul, MN.

Donaldson, P. A., Anderson, T., Lane, B. G., Davidson, A. L., and Simmonds, D. H. 2001. Soybean plants expressing an active oligomeric oxalate oxidase from the wheat gf-2.8 (germin) gene are resistant to the oxalate-secreting pathogen Sclerotinia sclerotiorum. Physiol. Mol. Plant Pathol. 59:297-307.

Dumas, B., Freyssinet, G., and Pallett, K. E. 1995. Tissue-specific expression of germin-like oxalate oxidase during development and fungal infection of barley seedlings. Plant Physiol. 107:1091-1096.

Farr, D. F., and Rossman, A. Y. 2017. Fungal Databases, U.S. National Fungus Collections. ARS, USDA. Retrieved December 2, 2017, from https://nt.arsgrin.gov/fungaldatabases/

Galloway, L. D. 1935. India: New plant diseases recorded in 1934. Int. Bull. Plant Prot. 11:176-178.

Gleason, M. L., Daughtrey, M. L., Chase, A. R., Moorman, G. W., and Mueller, D. S. 2009. Diseases of Herbaceous Perennials. American Phytopathological Society, St. Paul, MN.

Godoy, G., Steadman, J. R., Dickman, M. B., and Dam, R. 1990. Use of mutants to demonstrate the role of oxalic acid in pathogenicity of Sclerotinia sclerotiorum on Phaseolus vulgaris. Physiol. Mol. Plant Pathol. 37:179-191.

Grabowski, M. A., and Malvick, D. K. 2015. Evaluation of annual bedding plants for resistance to white mold. HortScience 50:259-262.

Grabowski, M. A., and Malvick, D. K. 2017. Evaluation of ornamental tropical plants for resistance to white mold caused by Sclerotinia sclerotiorum. HortScience 52:1375-1379.

Guimaraes, R. L., and Stotz, H. U. 2004. Oxalate production by Sclerotinia sclerotiorum deregulates guard cells during infection. Plant Physiol. 136: 3703-3711.

Hartman, G. L., Rupe, J. C., Sikora, E. J., Domier, L. L., Davis, J. A., and Steffey, K. L. 2015. Compendium of Soybean Diseases and Pests. American Phytopathological Society, St. Paul, MN.

Harveson, R., Markell, S., Block, C., and Gulya, T. 2016. Compendium of Sunflower Diseases. American Phytopathology Press, St. Paul, MN.

Hegedus, D. D., Li, R., Buchwaldt, L., Parkin, I., Whitwill, S., Coutu, C., Bekkaoui, D., and Rimmer, S. R. 2008. Brassica napus possesses an expanded set of polygalacturonase inhibitor protein genes that are differentially regulated in response to Sclerotinia sclerotiorum infection, wounding and defense hormone treatment. Planta 228:241-253.
Hilu, K. W. 1984. Leaf epidermes of Andropogon sect. Leptopogon (Poaceae) in North America. Syst. Bot. 9:247-257

Hu, X., Bidney, D. L., Yalpani, N., Duvick, J. P., Crasta, O., Folkerts, O., and Lu, G. 2003. Overexpression of a gene encoding hydrogen peroxide-generating oxalate oxidase evokes defense responses in sunflower. Plant Physiol. 133: $170-181$

Hurkman, W. J., and Tanaka, C. K. 1996. Germin gene expression is induced in wheat leaves by powdery mildew infection. Plant Physiol. 111:735-739.

Hysek, J., Tempirova, Z., Vlk, J., Curiova, S., and Vyzkumny, U. R. V. 1986. Mycoflora of Stored Cereal Seed. Rostl. Vyroba - UVTIZ Czechoslov

Koike, S. T. 2007. Vegetable diseases: A color handbook. Plant protection handbooks series. Academic Press, Burlington, MA.

Lumsden, R. D., and Dow, R. L. 1973. Histopathology of Sclerotinia sclerotiorum infection of bean. Phytopathology 63:708-715.

Lumsden, R. D., and Wergin, W. P. 1980. Scanning-electron microscopy of infection of bean by species of Sclerotinia. Mycologia 72:1200-1209.

Madden, L., Hughes, G., and van den Bosch, F. 2007. The Study of Plant Disease Epidemics. American Phytopathological Society, St. Paul, MN.

Marciano, P., Di Lenna, P., and Magro, P. 1983. Oxalic acid, cell wall-degrading enzymes and $\mathrm{pH}$ in pathogenesis and their significance in the virulence of two Sclerotinia sclerotiorum isolates on sunflower. Physiol. Plant Pathol. 22: 339-345.

Miclauş, D., Sin, G., Damian, V., and Guran, M. 1988. Presence and spread of Sclerotinia sclerotiorum (Lib.) de Bary on seeds of various cereal and industrial crops. Inst. Cercet. Cereale Plante The. 56:169-188.

Noyes, R. D., and Hancock, J. G. 1981. Role of oxalic acid in Sclerotinia wilt of sunflower. Physiol. Plant Pathol. 18:123-132.

Orshinsky, A. M., Boehm, M. J., and Boland, G. J. 2012. Plant wounding and Ophiostoma mitovirus $3 a$ (OMV3a) influence infection of creeping bentgrass by Sclerotinia homoeocarpa. Can. J. Plant Pathol. 34:493-506.

Poole, R. F. 1922. The sclerotinia rot of celery. New Jersey Agricultural Experiment Station.

Prats, E., Bazzalo, M. E., León, A., and Jorrín, J. V. 2003. Accumulation of soluble phenolic compounds in sunflower capitula correlates with resistance to Sclerotinia sclerotiorum. Euphytica 132:321-329.

Richardson, M. J. 1990. An annotated list of seed-borne diseases. Annot. List Seed-Borne Dis. No. 23. Commonwealth Mycological Institute, UK.

Schwartz, H. F., and Steadman, J. R. 1978. Factors affecting sclerotium populations of, and apothecium production by, Sclerotinia sclerotiorum. Phytopathology 68:383-388.

Urdangarín, C., Regente, M. C., Jorrín, J., and de la Canal, L. 1999. Sunflower coumarin phytoalexins inhibit the growth of the virulent pathogen Sclerotinia sclerotiorum. J. Phytopathol. 147:441-443.

Wang, Z., Tan, X., Zhang, Z., Gu, S., Li, G., and Shi, H. 2012. Defense to Sclerotinia sclerotiorum in oilseed rape is associated with the sequential activations of salicylic acid signaling and jasmonic acid signaling. Plant Sci. 184:75-82.

Warren, H. L., and Frederiksen, R. A. 1986. Compendium of Sorghum Diseases American Phytopathological Society, St. Paul, MN.

White, D. G., and Munkvold, G. P. 2016. Compendium of Corn Diseases American Phytopathological Society, St. Paul, MN.

Zhao, J., Wang, J., An, L., Doerge, R. W., Chen, Z. J., Grau, C. R., Meng, J., and Osborn, T. C. 2007. Analysis of gene expression profiles in response to Sclerotinia sclerotiorum in Brassica napus. Planta 227:13-24.

Zhou, F., Zhang, Z., Gregersen, P. L., Mikkelsen, J. D., de Neergaard, E., Collinge, D. B., and Thordal-Christensen, H. 1998. Molecular characterization of the oxalate oxidase involved in the response of barley to the powdery mildew fungus. Plant Physiol. 117:33-41. 